$3^{\text {rd }}$ AIAA Multidisciplinary Design Optimization Specialist Conference

23-26 April 2007, Honolulu, Hawaii

\title{
Design Optimization of a Space Launch Vehicle Using a Genetic Algorithm
}

\author{
Douglas J. Bayley*, Roy J. Hartfield, Jr. ${ }^{\dagger}$, John E. Burkhalter ${ }^{\ddagger}$, and Rhonald M. Jenkins! \\ Department of Aerospace Engineering \\ Auburn University \\ Auburn, AL 36849
}

Disclaimer: The views expressed in this paper are those of the author and do not reflect the official policy or position of the United States Air Force, Department of Defense, or the U.S. Government.

This paper describes an effort to optimize the design of an entire space launch vehicle to low-Earth (circular) orbit, consisting of multiple stages using a genetic algorithm (GA) with the goal of minimizing vehicle weight and ultimately vehicle cost. The entire launch vehicle system is analyzed using various multistage configurations to reach low-Earth orbit. Specifically, three and four-stage solid propellant vehicles have been analyzed. The vehicle performance modeling requires that analysis from four separate disciplines be integrated into the design optimization process. The disciplines of propulsion characteristics, aerodynamics, mass properties and flight dynamics have been integrated to produce a high fidelity system model of the entire vehicle. In addition, the system model has been validated using existing launch vehicle data. The cost model is mass-based and uses extensive historical data to produce a cost estimating relationship for a solid propellant vehicle. For the design optimization, the goals of the problem are for the GA to minimize the differences between the desired and actual orbital parameters. This ensures the payload achieves the desired orbit. One final goal is to minimize the overall vehicle mass thus minimizing the system cost per launch. The paper will represent the first effort of its kind to minimize solid propellant launch vehicle cost at the preliminary design level using a GA.

\section{Introduction}

The United States Air Force (USAF) continues to seek assured and affordable access to space. The current USAF vision for achieving this capability is called Operationally Responsive Space (ORS). One broad outcome of ORS is to produce a launch vehicle with the following goals: launch a 1,000 pound payload into low-Earth orbit at a cost of under \$5 million and launch the vehicle within 24 hrs of tasking.

In order to support ORS, the Defense Advanced Research Projects Agency (DARPA) and the USAF are "jointly sponsoring the Force Application and Launch from CONUS (FALCON) program to develop technologies and demonstrate capabilities that will enable transformational changes in global, time critical strike missions." "The goal of this program is to design a launch vehicle with a prompt global strike capability.

* PhD Candidate, Senior Member AIAA, Major, USAF

$\dagger$ Professor, Senior Member AIAA

$\ddagger$ Professor Emeritus, Associate Fellow AIAA

! Professor Emeritus, Senior Member AIAA 


\section{A. Optimization Techniques}

The goal of design optimization is to find the optimum (from the Latin word optimus, meaning best) solution to the design problem. Throughout history numerous techniques have been developed in order to carry out design optimization. Modern computers, with their incredibly fast computational power, have turned optimization theory into a rapidly growing branch of applied mathematics. Methods such as gradient methods, pattern search optimization, and design of experiments have all been successfully used in finding optimum solutions.

For the current study, the genetic algorithm (GA) has been chosen for the design optimization process. One of the main benefits of using a GA is the fact that the algorithm can start without a single point, or guess, to get the optimization running. The previously mentioned direct search and gradient methods all need an initial guess to the problem solution in order to "march" toward the desired optimized result; either a maximum or minimum value. Also, derivatives of the functions that describe the system are not required for the GA. This is critical due to the possibility of a large number of discrete variables being evaluated. The GA does not require that the functions be differentiable in every independent variable. Finally, achieving a global optimum is more likely through the use of this GA. The GA uses a population of guesses that are random and spread throughout the search space. Powerful operators such as selection, crossover and mutation help direct members of each population toward the desired goal(s) of the problem. A binary encoding system allows for a host of variables to be manipulated by the GA and then used in performance codes; called the objective function. The objective function determines the performance of each member of the population and the GA ranks each one according to how well it meets the desired goal(s).

\section{B. Recent Launch Vehicle Optimization Work}

Significant work has been done in recent years to advance the design and analysis of entire launch vehicle systems. Numerous efforts have resulted in the development of legacy codes that analyze the performance of solid and liquid propellant rockets. In addition, an aerodynamics model, mass properties model and six-degree-of-freedom (6DOF) flight dynamics simulator have all been used. In 1998, Anderson ${ }^{2}$ assembled these performance codes and created an objective function that could analyze the performance of an entire, single-stage solid propellant rocket vehicle. In addition, Anderson wrote the GA that was used in the design optimization of this vehicle. Using this GA and the objective function, in 2003 and 2006, Burkhalter, Jenkins, and Hartfield ${ }^{3-5}$ took the design optimization of missile systems further.

The foundation work necessary to use these performance codes and the GA to pursue the design optimization of space launch vehicles has been completed. In addition to analyzing the performance of each vehicle, a cost model has been written in order to bring an economic factor into the optimization process.

In recent years, evolutionary techniques have been used to solve a myriad of design optimization problems $^{5-7}$. Significant research has been performed in rocket-based vehicle design optimization using various evolutionary techniques ${ }^{8-19}$. Cost has also been considered in some studies $^{20-22}$. 


\section{System Modeling and Optimization Algorithm}

Modeling of the launch vehicle consists of employing a suite of performance codes which are based on physical models for the propulsion system, the mass properties, the aerodynamics, and the vehicle flight dynamics. All critical vehicle performance parameters are calculated using these performance codes. These performance codes form the basis for an objective function that interacts with the GA to produce possible design solutions. The results are used to determine how well each particular launch vehicle meets the desired goals of the design optimization.

\section{A. Genetic Algorithm (GA)}

For this study, a tournament based GA is used to control the design process. Specifically, the IMPROVE $3.1^{\odot} \mathrm{GA}$, developed by Anderson ${ }^{23}$, is configured to interact with the various system models that make up the objective function. The IMPROVE $3.1^{\circledR}$ GA uses the biological concept of generational adaptation to optimize a design problem which may contain numerous local optima ${ }^{23}$. Rather than define the first iteration, the user specifies a range (maximum, minimum, and resolution) for each design parameter, and the GA randomly generates a population of candidate solutions from parameters within those ranges. After each candidate is analyzed by performance codes, the GA ranks the candidates (members) in order of fitness, or how closely they match the objective function. The tournament method is then used to create the next generation of members, which will possess characteristics of the previous population but in different combinations which may result in better overall fitness. Over the course of many generations, the GA will find solution types that increasingly approach the target fitness.

The performance codes analyze each member generated by the GA to determine the overall performance of the vehicle. This allows the GA to find solution types that not only meet the target fitness but are also realistic.

\section{B. Propulsion Models}

After the GA has generated a set of design parameters, the first performance code to be used by the objective function is the solid propellant propulsion system model. This code analyzes the basic thrust characteristics of a solid propellant motor. Specific solid propellant properties are pre-loaded and additional properties are generated by the GA. This information is then used to calculate the thrust characteristics such as: thrust, burn time, grain mass, and combustion pressure. For example, the grain geometry of a solid propellant motor can be specified by the GA. From these values, the entire thrust profile of the motor is determined in the solid propellant propulsion system model. The development of this model was pioneered in the research performed by Hartfield, Jenkins, Burkhalter and Foster ${ }^{24}$.

For a multi-stage vehicle, the number of times the solid propellant propulsion system model is utilized corresponds to the number of stages in the vehicle. The propulsion characteristics of each stage are determined separately and in sequence.

\section{Mass \& Aerodynamic Properties Models}

Upon completion of the propulsion system analysis, the mass and aerodynamic properties are calculated. The process of determining the mass properties of the vehicle involves two sequential steps. First, the mass properties of the individual components of the launch vehicle are determined. These components can include the nosecone, the payload, an electronics section, motor casing, liner and nozzle. Next, using the mass properties of the individual components, the overall mass properties of the entire vehicle are determined. These values are then 
summarized to create a mass properties data file that is used in the six-degree-of-freedom (6DOF) flight dynamics simulator. The mass properties model calculates the mass, the location of the centers of gravity and the moments of inertia for all vehicle components along with the entire launch vehicle itself.

In 1990, Washington ${ }^{25}$ developed an aerodynamic prediction package, called AeroDesign, which is capable of determining the aerodynamic constants of axisymmetric missiles of circular cross-section with cruciform wings or fins. Using the AeroDesign package along with the known geometric parameters of the vehicle, the important aerodynamic coefficients are generated. Essential aerodynamic coefficients are determined for a range of flight Mach numbers and angles of attack.

\section{Six-Degree-of-Freedom (6DOF) Flight Dynamics Simulator}

The culmination of the vehicle performance analysis occurs in the six-degree-of-freedom (6DOF) flight dynamics simulator. A $7^{\text {th }} / 8^{\text {th }}$ order Runge-Kutta numerical method is used to integrate the equations of motion. Position, velocity and orientation of the vehicle are determined at small time intervals throughout the flight. The vehicle flies a ballistic trajectory with the goal of reaching the desired low-Earth orbit. Anderson ${ }^{2,11,12,18,19}$ performed significant work with this 6DOF flight dynamics simulator in the design optimization of single-stage, solid propellant tactical missiles.

\section{E. Cost Model}

The cost model used in this analysis was derived by Dr. Dietrich E. Koelle and published in his book Handbook of Cost Engineering for Space Transportation Systems, Revision 1, with TRANSCost $7.1^{26}$. The TRANSCost 7.1 cost model is broken into three submodels. These submodels are: the Development Cost Submodel, the Recurring Cost Submodel, and the Ground and Flight Operations Submodel. These various submodels employ system-level Cost Estimation Relationships (CERs) to predict cost. In addition, to bring more realism to the cost per launch determination, an Insurance Cost Submodel is included in the cost model.

\section{A. Validation Method}

\section{Model Validation}

The purpose of model validation is to verify that the results generated by the system model are both reasonable and realistic. How accurately the system model represents a real world system is very important. The degree of accuracy in the model is directly proportional to the confidence level in the results the model produces. Thus, model validation helps to provide this confidence in the results.

A method, previously used by Riddle ${ }^{27}$, has been employed for this study. This method begins by researching and choosing a launch vehicle that is similar to the system being modeled by the objective function. Next, as much information on the chosen vehicle is determined and appropriately hard-coded into the appropriate input locations for the objective function. This information includes physical size, thrust values and/or propellant types. The objective function, along with other design parameters, is then manipulated in an attempt to reproduce the characteristics of the real world example. Also, in order to attempt to match the real world example more closely, a design optimization can be run using the GA. The purpose of this optimization is not to maximize or minimize any particular vehicle performance characteristics but rather to allow the GA to "fine tune" the model by choosing the remaining unknown 
parameters so that the resulting vehicle matches, as closely as possible, the real world example. If the objective function can produce a launch vehicle that is strikingly similar to the real world example, given the real world example's known and GA determined parameters, then the validity of the model is substantially strengthened.

\section{B. Three and Four-Stage Solid Propellant Launch Vehicles}

For the current study, three and four-stage solid propellant launch vehicles have been validated against two real world examples. Given known parameters for the real world examples (payload mass, types of propellants, etc.), the system model was manipulated in an attempt to match the physical properties and the performance characteristics of the real world example. The known parameters used were:

- payload mass to orbit

- desired altitude and velocity

- individual stage geometry (diameter and length)

- individual stage propellants

In addition, the use of the propellant mass fraction $\left(f_{\text {prop }}\right)$ provides an important check on model validity. The equation for the propellant mass fraction comes from Humble, Henry and Larson ${ }^{28}$ and is given below in Equation 1:

$$
f_{\text {prop }}=\frac{m_{\text {prop }}}{m_{\text {prop }}+m_{\text {inert }}}
$$

where $m_{\text {prop }}$ is the mass of the propellant and $m_{\text {inert }}$ is the mass of the vehicle or stage minus the mass of the propellant and the mass of the payload (i.e. the dry mass). Also, according to Humble, Henry and Larson $^{28}$, the propellant mass fraction for solid propellant vehicles is desired to be around 0.90 .

The real world example chosen to validate the three-stage solid propellant launch vehicle was the Minuteman III intercontinental ballistic missile (ICBM). The Minotaur I space launch vehicle (SLV) was chosen to be the real world example for the validation of the four-stage solid propellant launch vehicle model.

A comparison of the results from the system model validation is shown in Table 1. From Table 1, the results show a good match has been obtained. The payload was a direct input to the objective function while the other parameters were calculated by the various performance models. 
Table 1: Four-Stage Solid Propellant Model vs. Minotaur I SLV Comparison

\begin{tabular}{|l|c|c|}
\hline \multicolumn{1}{|c|}{ Parameter } & Validation Model & Minotaur I SLV \\
\hline Payload & $738 \mathrm{lbm}$ & $738 \mathrm{lbm}$ \\
\hline Total Vehicle Weight & $78,090 \mathrm{lbm}$ & $79,800 \mathrm{lbm}$ \\
\hline Total Vehicle Length & $64.58 \mathrm{ft}$ & $63.02 \mathrm{ft}$ \\
\hline Total Vehicle $\mathrm{f}_{\text {prop }}$ & 0.9185 & 0.8998 \\
\hline Final Altitude & $2,425,999 \mathrm{ft}$ & $2,430,000 \mathrm{ft}$ \\
\hline Final Velocity & $25,002 \mathrm{ft} / \mathrm{s}$ & $25,004 \mathrm{ft} / \mathrm{s}$ \\
\hline Cost per Launch & $\$ 51.95 \mathrm{million}$ & $\$ 51.21 \mathrm{million}$ \\
\hline Adjusted Cost per Launch & & $\$ 29.76 \mathrm{million}$ \\
\hline Advertised Cost per Launch & & $\$ 20.00 \mathrm{million}$ \\
\hline
\end{tabular}

The model produces a vehicle very similar to the Minotaur I SLV. The total weight of the vehicle is about 1,700 pounds less than the weight of the Minotaur I SLV. Also, the performance parameters for the model closely match the desired orbital velocity and orbital altitude for the Minotaur I SLV.

The subjective nature of vehicle cost is apparent in the cost comparison. Using the published mass values for the Minotaur I SLV and applying the cost model developed for this study, the cost per launch of the Minotaur I SLV is \$51.21 million in 2003 dollars. This is roughly about the same as the cost per launch of the vehicle generated by the model ( $\$ 51.95$ million vs. \$51.21 million). In reality, there is no recurring cost for the first two stages of the Minotaur I SLV since those stages come from surplus Minuteman II ICBMs that have already been built. An adjustment to the cost model to allow for this yields a cost per launch of the Minotaur I SLV to be $\$ 29.76$ million. Finally, the advertised cost per launch of the Minotaur I SLV is given as $\$ 20.00$ million. There is currently no data in an open source format that explains how the $\$ 20.00$ million value is determined.

\section{Optimization Results}

Design optimization results for three and four-stage solid propellant launch vehicles are presented here. An initial launch vehicle optimization has been performed in order to verify that both the optimization process and the problem set-up work. After this initial optimization is discussed, the results of the three and four-stage design optimization are analyzed. For each design optimization that was performed, the GA was configured to run in a non-pareto format. This format allows for a global parameter set that meets the desired values of the specified design goals.

\section{A. Initial Launch Vehicle Optimization}

The purpose of this initial design optimization was to determine if a three-stage solid propellant rocket could be designed in order to achieve the desired low-Earth orbit. The desired mission statistics for this vehicle are listed in Table 2. 
Table 2: Initial Launch Vehicles Mission Statistics

\begin{tabular}{|r|l|}
\hline Payload Mass & $1,000 \mathrm{lbm}$ \\
\hline Launch Site & Vandenberg AFB, CA $\left(34.6^{\circ} \mathrm{N}, 120.6^{\circ} \mathrm{W}\right)$ \\
\hline Launch Direction & Due North $\left(0^{\circ}\right.$ Azimuth or i $=90^{\circ} /$ polar orbit $)$ \\
\hline Desired Orbital Velocity & $24,550 \mathrm{ft} / \mathrm{s}$ \\
\hline Desired Orbital Altitude & $2,430,000 \mathrm{ft}$ \\
\hline
\end{tabular}

The two goals for this optimization were:

Goal \#1: minimize the difference between the desired orbital velocity (vorb) and the actual velocity of the vehicle (vt1)

Goal \#2: minimize the difference between the desired orbital altitude (altorb) and the actual altitude of the vehicle (alt1)

Note that this first case is merely a demonstration of the feasibility of finding a workable solution using the GA. The design optimization for this three-stage solid propellant rocket uses a population size of 400 members. The optimization is intended to run for 150 generations but the optimum solution that met both goals was actually achieved by generation \#43 (see Figures 1 \& 2). Figures 1 and 2 show how the best performer improved as each generation proceeded. In Figure 1, the velocity goal was met by generation \#23, while in Figure 2, the altitude goal was met by generation $\# 43$.

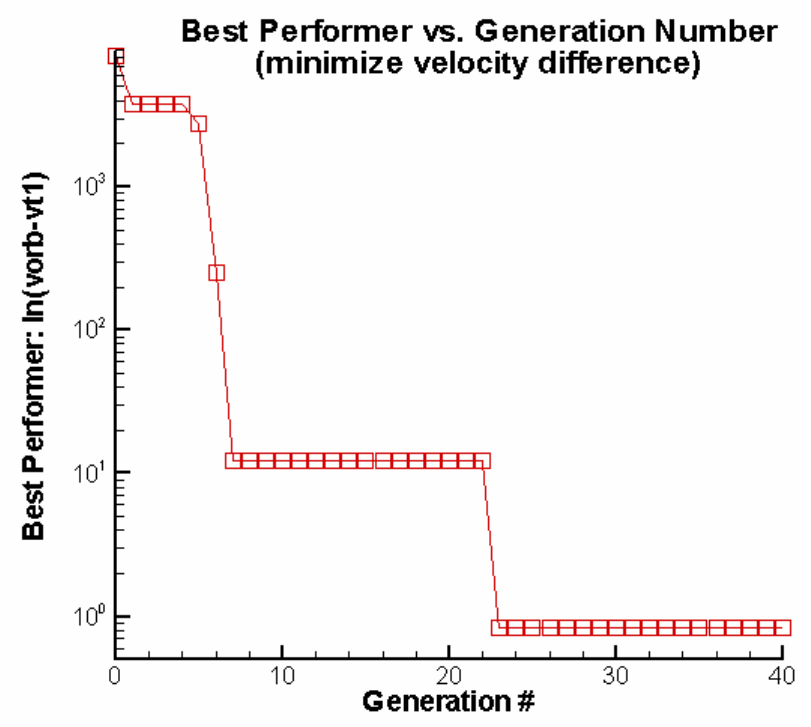

Figure 1. Progress of Best Performer to Meet Goal \#1 


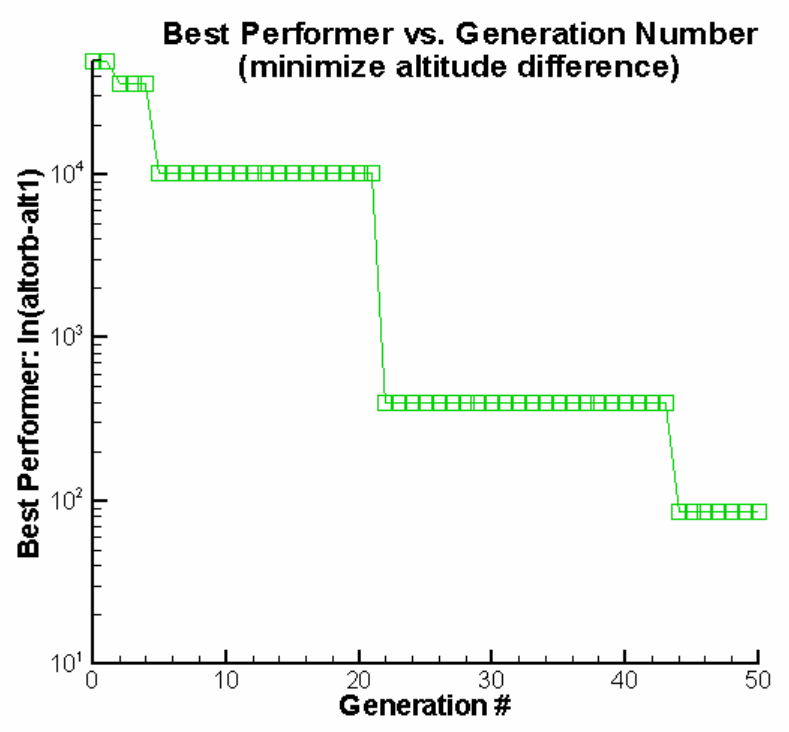

Figure 2. Progress of Best Performer to Meet Goal \#2

The best performing vehicle of the final generation was used to display the actual performance of the optimum design. This vehicle would thus be the three-stage solid rocket that most closely meets the desired performance goals. The design variables (i.e. the 34 GA variables) that created the best performer were run in a single-run format to generate data files which are summarized in the following paragraphs and figures.

Figures 3 thru 7 show the important performance parameters of this vehicle. Looking at Figure 3, it appears that the GA selected very similar dimensions for the $1^{\text {st }}$ and $2^{\text {nd }}$ stages of the rocket and a relatively small sized $3^{\text {rd }}$ stage in order to meet both design goals. The ballistic flight trajectory of the vehicle is shown in Figure 4 where the altitude has reached the orbital altitude at the top of the parabolic trajectory. The next three figures display the changes in vehicle performance with time. Figure 5 shows the Thrust vs. Time characteristics. Three distinct "humps" in the curve show where the thrust in each stage tails off and then the next stage abruptly starts. There is no delay between the end of one stage and the start of another. Figure 6 (Vehicle Mass vs. Time) shows how the mass of the vehicle continuously decreases until burnout of Stage 3 at approximately 107 seconds. Finally, the Velocity vs. Time plot in Figure 7 displays the increase in velocity during powered flight and then the slight decrease in velocity during ballistic flight to maximum altitude. 


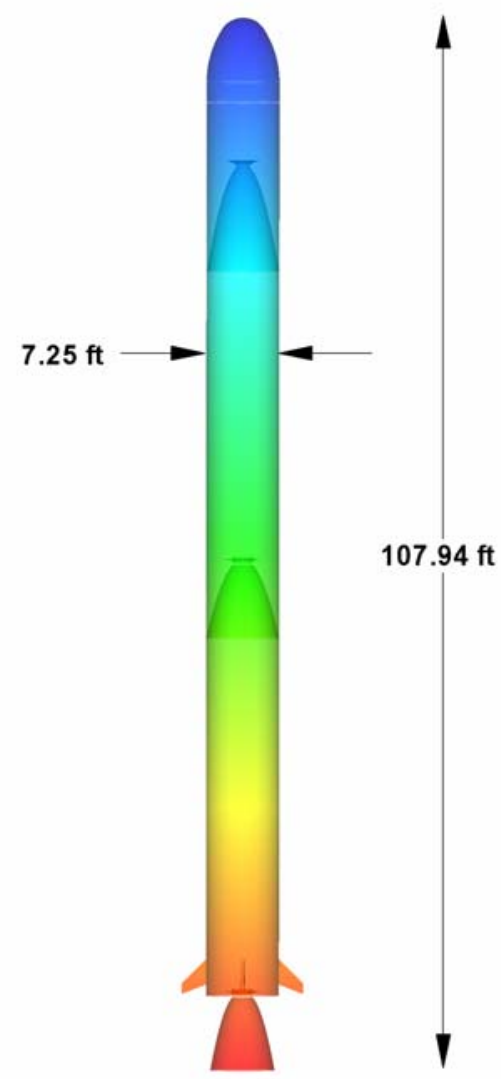

Figure 3. Three-Stage Solid Propellant Launch Vehicle Schematic

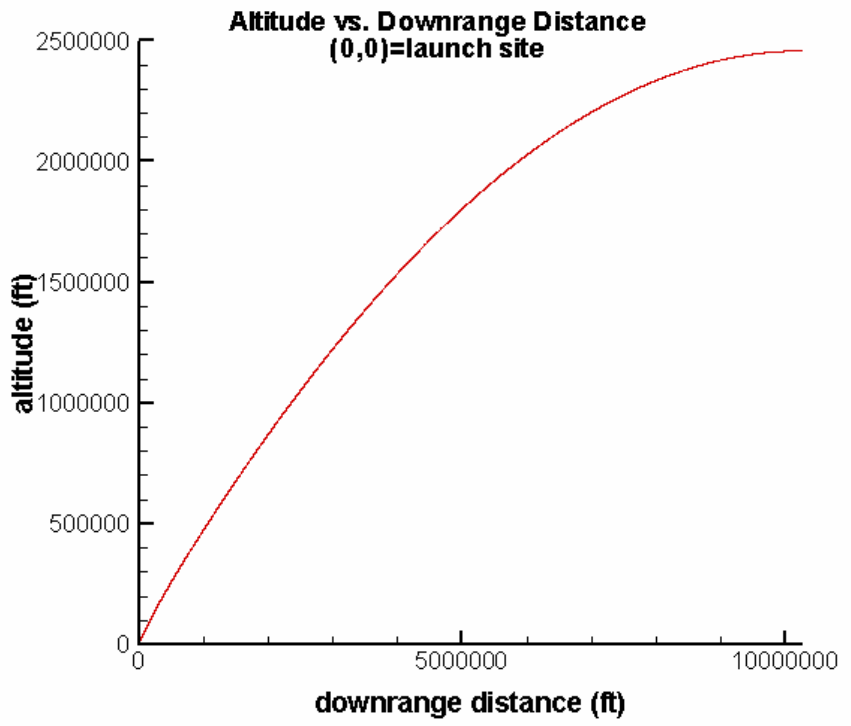

Figure 4. Altitude vs. Downrange Distance for Best Performer 


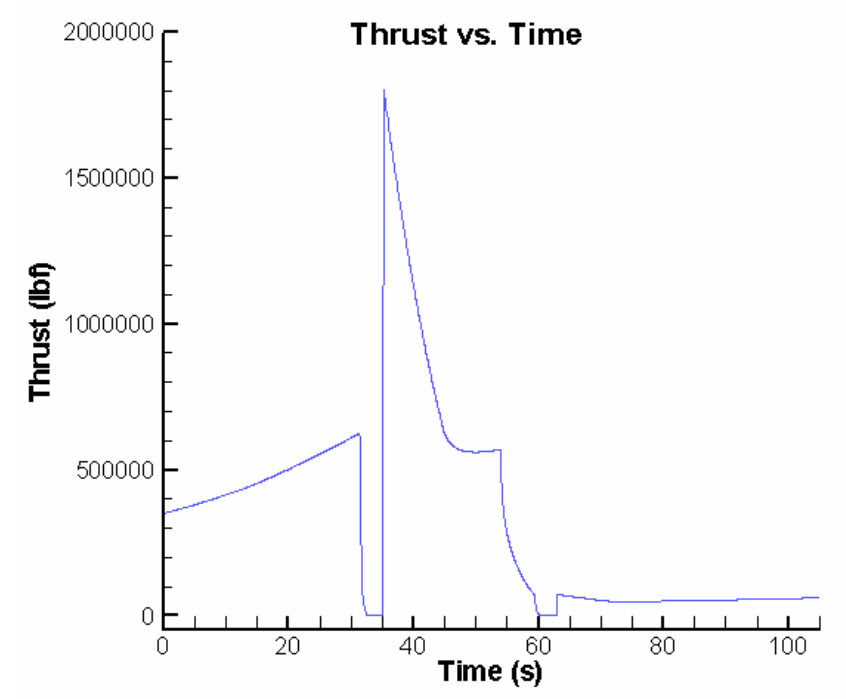

Figure 5. Thrust vs. Time for Best Performer

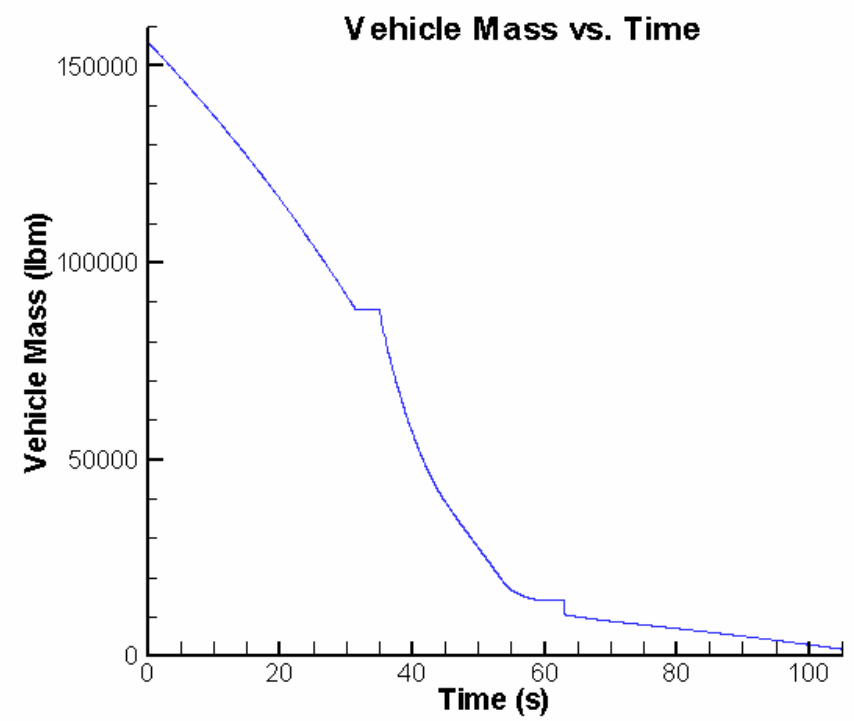

Figure 6. Vehicle Mass vs. Time for Best Performer 


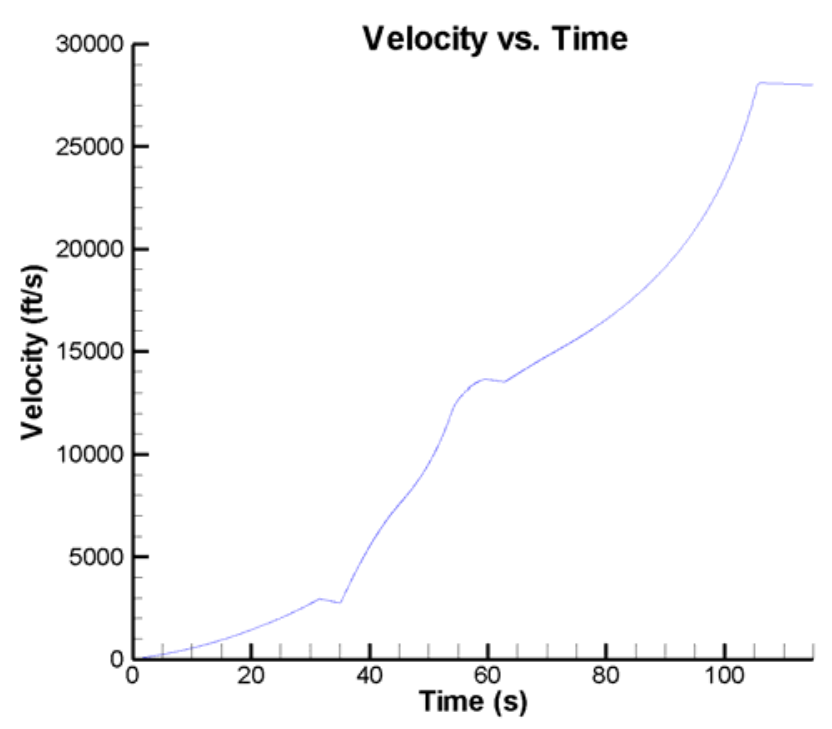

Figure 7. Velocity vs. Time for Best Performer

The next two design optimizations presented here are for the three and four-stage solid propellant launch vehicles. Unlike the initial launch vehicle, these optimizations have built upon the results from the model validation process. The primary focus for these vehicles was to attempt to improve on the launch vehicle design. One important note: the Minuteman III ICBM is not an orbital vehicle. As a result, the three-stage solid propellant launch vehicle was optimized to attain a low-Earth orbit. Thus, a direct comparison between the two vehicles cannot be made. The desired mission statistics for both vehicles are listed in Table 3. For comparison, the mission statistics of the Minotaur I SLV are also included.

Table 3: Solid Propellant Launch Vehicles Mission Statistics

\begin{tabular}{|l|c|c|c|}
\hline & $\begin{array}{c}\text { Three-Stage } \\
\text { Solid }\end{array}$ & $\begin{array}{c}\text { Four-Stage } \\
\underline{\text { Solid }}\end{array}$ & $\frac{\underline{\text { Minotaur I }}}{\underline{\text { SLV }}}$ \\
\hline Payload & $\begin{array}{c}1,000 \mathrm{lbm} \\
738 \mathrm{lbm}\end{array}$ & $738 \mathrm{lbm}$ \\
\hline Launch Site & VAFB & VAFB & VAFB \\
\hline Launch Direction & $\begin{array}{c}\text { Due North } \\
0^{\circ} \text { Azimuth }\end{array}$ & $\begin{array}{c}\text { Due North } \\
0^{\circ} \text { Azimuth }\end{array}$ & $\begin{array}{c}\text { Slightly } \\
\text { Northwest }\end{array}$ \\
\hline Orbit Type & $\begin{array}{c}\mathrm{i}=90^{\circ} \\
\text { polar orbit }\end{array}$ & $\begin{array}{c}\mathrm{i}=90^{\circ} \\
\text { polar orbit }\end{array}$ & $\begin{array}{c}\mathrm{i}=97.5^{\circ} \\
\text { sun-sync orbit }\end{array}$ \\
\hline Desired Orbital Altitude & $2,430,000 \mathrm{ft}$ & $2,430,000 \mathrm{ft}$ & $2,430,000 \mathrm{ft}$ \\
\hline Desired Orbital Velocity & $24,550 \mathrm{ft} / \mathrm{s}$ & $25,000 \mathrm{ft} / \mathrm{s}$ & $25,000 \mathrm{ft} / \mathrm{s}$ \\
\hline
\end{tabular}

\section{B. Three-Stage Solid Propellant Launch Vehicle}

A successful design optimization of a three-stage solid propellant launch vehicle has been performed. Figure 8 shows a schematic of the best performer of the design optimization of the three-stage solid propellant vehicle for a launch out of Vandenberg AFB, CA. 


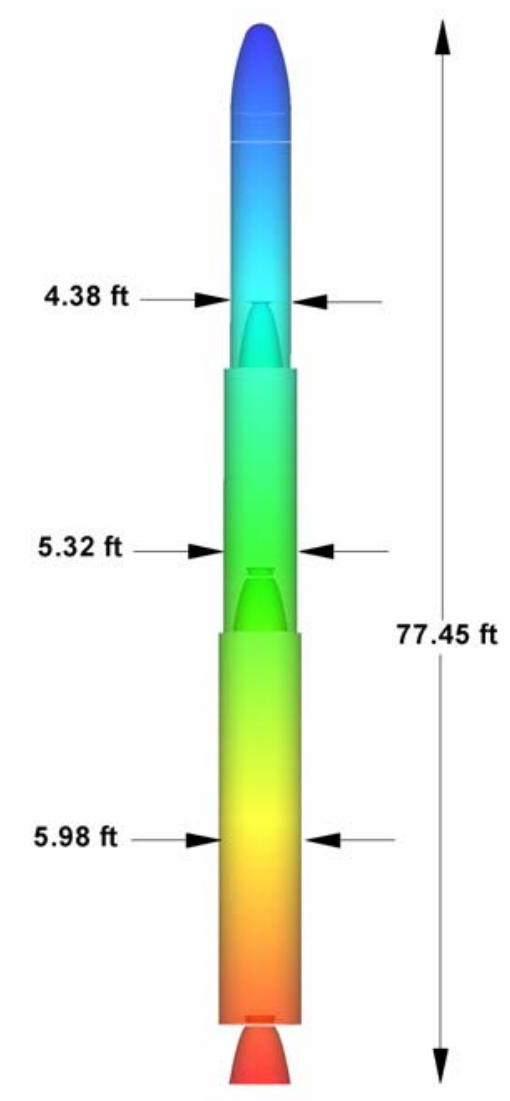

Figure 8. Three-Stage Solid Propellant Launch Vehicle Schematic (Vandenberg)

The important characteristics of the optimized three-stage solid propellant vehicle are shown in Table 4. The final altitude of the vehicle is within 10,000 $\mathrm{ft}$ of the desired orbital altitude. The final velocity is slightly above the desired orbital velocity which ensures the payload reaches orbit. Thus, the optimized vehicle meets the required orbital parameters thus reaching orbit and ensuring mission success.

From a mass fraction perspective, the entire vehicle as well as the individual stages, closely match the desired value of propellant mass fraction (0.90) given by Humble, Henry and Larson $^{26}$. The propellant mass fraction ( $f_{\text {prop }}$ ) for the entire vehicle is 0.9072 which is as expected. For each of the three individual stages (Stage 1: 0.9139, Stage 2: 0.8882, Stage 3: 0.9241), the propellant mass fraction has good values.

The first stage thrust provides the initial high thrust (331,972 lbf) required to lift the vehicle off the ground with a thrust-to-weight ratio of over 3-to-1. The Stage 2 and Stage 3 thrust values drop off but still provide the necessary force to get the payload into the desired lowEarth orbit.

Finally, the cost per launch of $\$ 49.71$ million in 2003 dollars is a moderate price for an expendable launch vehicle. It is not exceptionally cheap but it also is not prohibitively expensive. The total vehicle mass of 89,906 pounds is the reason for this particular price. This value of the total vehicle mass is an improvement over the initial launch vehicle discussed in the previous section. However, this value is over 10,000 pounds higher than the Minuteman III 
ICBM (79,432 lbm) and the Minotaur I SLV (79,800 lbm). The Minuteman III ICBM is not an orbital vehicle. This would suggest that an additional 10,000 pounds is required to enable the launch vehicle to go from sub-orbital speed $(22,000 \mathrm{ft} / \mathrm{s})$ to orbital velocity $(24,550 \mathrm{ft} / \mathrm{s})$.

Table 4: Summary of Three-Stage Solid Propellant Launch Vehicle Characteristics (Vandenberg)

\begin{tabular}{|l|c|l|c|}
\hline Entire Vehicle & & Stage 1 & \\
\hline Final Altitude & $2,439,276 \mathrm{ft}$ & Initial Thrust & $331,972 \mathrm{lbf}$ \\
\hline Final Velocity & $24,595 \mathrm{ft} / \mathrm{s}$ & $\mathrm{f}_{\text {prop }}$ & 0.9139 \\
\hline Total Vehicle Mass & $89,906 \mathrm{lbm}$ & Stage 2 & \\
\hline Total Vehicle Length & $77.45 \mathrm{ft}$ & Initial Thrust & $82,093 \mathrm{lbf}$ \\
\hline Total Vehicle f $\mathrm{prop}$ & 0.9072 & $\mathrm{f}_{\text {prop }}$ & 0.8882 \\
\hline Cost per Launch & $\$ 49.71 \mathrm{million}$ & Stage 3 & \\
\hline & & Initial Thrust & $67,192 \mathrm{lbf}$ \\
\hline & & $\mathrm{f}_{\text {prop }}$ & 0.9241 \\
\hline
\end{tabular}

\section{Four-Stage Solid Propellant Launch Vehicle}

The design optimization of the four-stage solid propellant launch vehicle produced an optimized vehicle with improved characteristics. Figure 9 shows a schematic comparing the three different resulting launch vehicles: the Minotaur I SLV, the vehicle produced by the validation model, and the vehicle produced by the design optimization process.
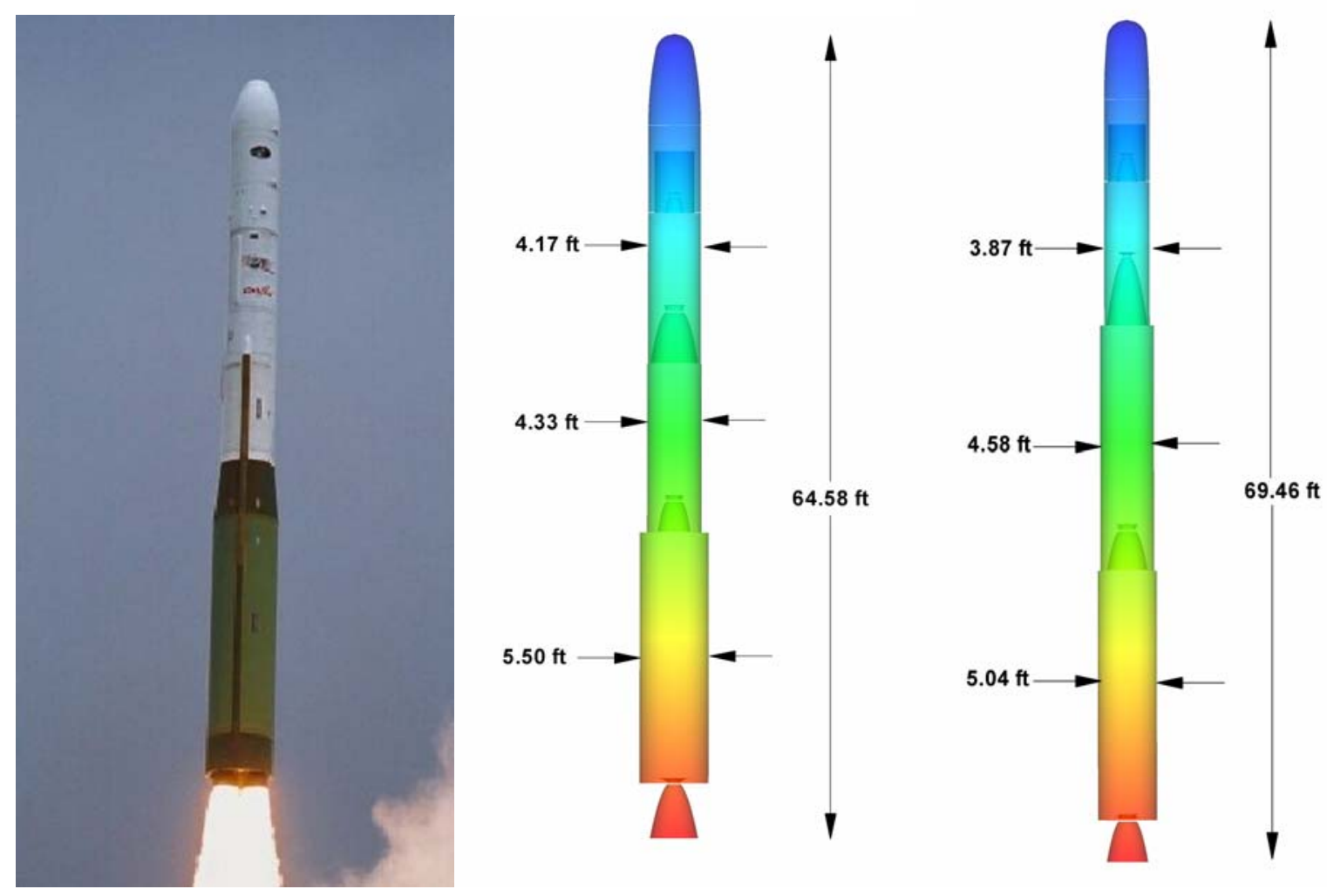

Figure 9. Schematic of Four-Stage Solid Propellant Launch Vehicles (Ref. 29: http://www.orbital.com/SpaceLaunch/Minotaur/index.html) 
A comparison of the different four-stage solid propellant launch vehicles is shown in Table 5. Again, the payload was a direct input to the objective function. Also, the first two goals for this optimization were to minimize the difference between the desired orbital parameters and the performance parameters. The third goal involved minimizing the total vehicle mass. There is significant improvement in the optimized vehicle over the Minotaur I SLV and the validation model. The best performer from the design optimization of the fourstage solid propellant launch vehicle weighs 19,000 pounds less than the Minotaur I SLV. This savings comes primarily from the difference in the mass of the Stage 1 propellants. The Stage 1 propellant mass in the optimized vehicle is 30,017 pounds versus 45,371 pounds for the Minotaur I SLV. This reduction in propellant mass was probably also aided by the choice of propellants for the individual stages.

The propellant mass fractions $\left(f_{\text {prop}}\right)$ for all three vehicles closely match the desired value of 0.90 . It should be noted that the optimized vehicle produces a very good propellant mass fraction $(0.8976)$ while at the same time reducing the total vehicle mass. This adds additional confidence to the system model while at the same time improving the overall vehicle design.

The optimized vehicle also provides about a \$5 million savings in cost per launch over the Minotaur I SLV and the validation model. Using the TRANSCost 7.1 cost model for the published mass values of the Minotaur I SLV ${ }^{30}$ resulted in a cost per launch of $\$ 51.21$ million. The optimized four-stage solid propellant launch vehicle yielded a cost per launch of \$46.07 million. While this cost savings is promising, it still does not reach the advertised cost per launch for the Minotaur I SLV of \$20 million.

All three vehicles are very similar in terms of physical characteristics. One possible reason for this is that restrictions were placed on the range of values of design parameters for the GA. The length and diameter of a particular stage could not be larger than the stage above it. As a result, the GA chose to lengthen the vehicle and slightly reduce the stage diameters. The main difference between the vehicles is that the optimized vehicle has a higher total length than the Minotaur I SLV and the validation model. Since the Minotaur I SLV uses decommissioned Minuteman II ICBMs for its first two stages, the physical characteristics of those two stages are pre-determined.

This design optimization was highly successful in generating an improved launch vehicle design. Instead of finding a truly global optimum solution (a very difficult task), a powerful aspect of the GA is its ability to improve on an existing design. As a result, a good validation of the system model is very important since it lays the groundwork for the design optimization process.

Table 5: Comparison of Four-Stage Solid Propellant Launch Vehicles

\begin{tabular}{|l|c|c|c|}
\hline & Minotaur I SLV & Validation Model & Optimized Vehicle \\
\hline Payload & $738 \mathrm{lbm}$ & $738 \mathrm{lbm}$ & $738 \mathrm{lbm}$ \\
\hline Total Vehicle Weight & $79,800 \mathrm{lbm}$ & $78,090 \mathrm{lbm}$ & $60,690 \mathrm{lbm}$ \\
\hline Total Vehicle Length & $63.02 \mathrm{ft}$ & $64.58 \mathrm{ft}$ & $69.46 \mathrm{ft}$ \\
\hline Total Vehicle $\mathrm{f}_{\text {prop }}$ & 0.8998 & 0.9185 & 0.8976 \\
\hline Final Altitude & $2,430,000 \mathrm{ft}$ & $2,425,999 \mathrm{ft}$ & $2,430,505 \mathrm{ft}$ \\
\hline Final Velocity & $25,004 \mathrm{ft} / \mathrm{s}$ & $25,002 \mathrm{ft} / \mathrm{s}$ & $25,036 \mathrm{ft} / \mathrm{s}$ \\
\hline Cost per Launch & $\$ 51.21 \mathrm{million}$ & $\$ 51.95 \mathrm{million}$ & $\$ 46.07 \mathrm{million}$ \\
\hline Advertised Cost per Launch & $\$ 20.00 \mathrm{million}$ & & \\
\hline
\end{tabular}




\section{Summary and Conclusion}

The design optimization of three and four-stage solid propellant launch vehicles has been performed. An objective function that modeled the physical and performance characteristics of the launch vehicles was used. A previously developed GA was used to optimize the design. The analysis from these optimizations has shown encouraging results in the ability to model and optimize launch vehicle systems.

The entire launch vehicle was modeled using a suite of codes that covered four design disciplines. Propulsion/thrust characteristics were modeled for solid propellant motors. Mass and aerodynamic properties were included in the objective function. Additionally, a 6DOF flight dynamics simulator was used to fly the vehicle into orbit. Finally, unique to this analysis, a cost model was utilized in order to provide cost per launch information on these vehicles.

Model validation is important in determining the accuracy of the results. For this study, the three and four-stage solid propellant launch vehicle models were validated against real world systems. The three-stage model was successfully validated against the Minuteman III ICBM and the four-stage model validated against the Minotaur I SLV. Both validations produced accurate representations of their respective launch vehicles.

The design optimizations have provided good results for three and four-stage solid propellant launch vehicles. Specifically, the design optimization of the four-stage solid produced a vehicle with some improved characteristics over the Minotaur I SLV. A mass savings of 19,000 pounds was obtained while still meeting the desired orbital altitude and orbital velocity parameters.

\section{Acknowledgments}

This work has been undertaken by D.J. Bayley through the support of the United States Air Force. Additionally, D.J. Bayley would like to thank Mr. Scott Schonemann of Orbital Sciences Corporation for providing information on the Minotaur I SLV.

\section{References}

1. System Description: "Force Application and Launch from CONUS (FALCON)”, http://www.globalsecurity.org/space/systems/falcon.htm

2. Anderson, M.B., "Design of a Missile Interceptor Using a Genetic Algorithm”, Doctoral Dissertation, Auburn University, 1998.

3. Burkhalter, J.E., Jenkins, R.M., and Hartfield, R.J., “Genetic Algorithms for Missile Analysis

- Final Report”, Submitted to Missile and Space Intelligence Center, Redstone Arsenal, AL, 35898, February 2003.

4. Hartfield, R.J., Burkhalter, J.E., Jenkins, R.M., and Metts, J.G., “Genetic Algorithm Upgrade Final Report”, Submitted to Missile and Space Intelligence Center, Redstone Arsenal, AL, 35898, June 2005, Reference Contract No. HHM402-04-P-0061.

5. Hartfield, R.J., Jenkins, R.M., and Burkhalter, J.E., "Ramjet Powered Missile Design Using a Genetic Algorithm,” AIAA Paper 2004-0451, Jan. 2004.

6. Budianto, J., and Olds, J., "Design and Deployment of a Satellite Constellation Using Collaborative Optimization,” Journal of Spacecraft and Rockets, Vol. 41, No. 6, 2004, pp. 956963.

7. Lian, Y., and Liou, M., "Multi-Objective Optimization of Transonic Compressor Blade Using Evolutionary Algorithm,” Journal of Propulsion and Power, Vol. 21, No. 6, 2005, pp. 979-987. 8. Brown, N., and Olds, J., "Evaluation of Multidisciplinary Optimization (MDO) Technique Applied to a Reusable Launch Vehicle,” AIAA Paper 2005-707, Jan. 2005. 
9. Tsuchiya, T., and Mori, T., "Orbital Design of Two-Stage-to-Orbit Space Planes with Airbreathing Engines,” Journal of Spacecraft and Rockets, Vol. 42, No. 1, 2005, pp. 90-97. 10. Casalino, L., and Pastrone, D., "Optimal Design and Control of Hybrid Rockets for Access to Space,” AIAA Paper 2005-3547, July 2005.

11. Anderson, M.B., Burkhalter, J.E., and Jenkins, R.M., "Design of an Air to Air Interceptor Using Genetic Algorithms", AIAA Paper 99-4081, August 1999.

12. Anderson, M.B., Burkhalter, J.E., and Jenkins, R.M., "Intelligent Systems Approach to Designing an Interceptor to Defeat Highly Maneuverable Targets”, AIAA Paper 2001-1123, January 2001.

13. Chernyavsky, B., Stepanov, V., Rasheed, K., Blaize, M., and Knight, D., “3-D Hypersonic Inlet Optimization Using a Genetic Algorithm”, AIAA Paper 98-3582, July 1998.

14. Shelton, J., Frederick, R., Wilhite, A., "Launch Vehicle Propulsion Design with Multiple Selection Criteria,” AIAA Paper 2005-3851, July 2005.

15. Portz, R., "Launch Vehicle Design Features for Minimum Cost," AIAA Paper 2004-3562, July 2004.

16. Braun, R.D., Moore, A.A., and Kroo, I.M., "Collaborative Approach to Launch Vehicle Design,” Journal of Spacecraft and Rockets, Vol. 34, No. 4, 1997, pp. 478-486.

17. Wollam, J., Kramer, S., and Campbell, S., "Reverse Engineering of Foreign Missiles via Genetic Algorithm,” AIAA Paper 2000-0685, Jan. 2000

18. Anderson, M.B., Burkhalter, J.E., and Jenkins, R.M., "Multi-Disciplinary Intelligent Systems Approach to Solid Rocket Motor Design, Part I: Single and Dual Goal Optimization,” AIAA Paper 2001-3493, July 2001.

19. Anderson, M.B., Burkhalter, J.E., and Jenkins, R.M., "Multi-Disciplinary Intelligent Systems Approach to Solid Rocket Motor Design, Part II: Multiple Goal Optimization,” AIAA Paper 2001-3494, July 2001.

20. Wertz, J.R., "Responsive Launch Vehicle Cost Model,” AIAA Paper RS2-2004-2004, April 2004.

21. Unal, R., Braun, R.D., Moore, A.A., and Lepsch, R.A., "Design Optimization for Cost Using Genetic Algorithms," Proceedings of the $17^{\text {th }}$ Annual Conference of the International Society of Parametric Analysts, May 1995, pp. 183-191.

22. Olds, J.R. and Lee, H., "Application of a New Economic Analysis Tool to a Two-Stage-toOrbit RBCC Launch Vehicle,” AIAA Paper 1996-4092, Sept. 1996.

23. Anderson, M.B., "Users Manual for IMPROVE ${ }^{\complement}$ Version 2.8: An Optimization Software Package Based on Genetic Algorithms”, Sverdrup Technology Inc. / TEAS Group, Eglin AFB, FL, March 6, 2001.

24. Hartfield, R.J., Jenkins, R.M., Burkhalter, J.E., and Foster, W., “Analytical Methods for Predicting Grain Regression in Tactical Solid-Rocket Motors,” Journal of Spacecraft and Rockets, Vol. 41, No. 4, July-August 2004, pp. 689-693.

25. Washington, W.D., "Missile Aerodynamic Design Program”, 1980, 1990.

26. Koelle, D.E., Handbook of Cost Engineering for Space Transportation Systems, Revision 1, with TRANSCost 7.1, TransCostSystems, Ottobrunn, Germany, 2003.

27. Riddle, D.B., Hartfield, R.J., Burkhalter, J.E., Jenkins, R.J., “Genetic Algorithm Optimization of Liquid Propellant Missile Systems,” AIAA Paper 2007-362, January 2007. 28. Humble, Ronald W., Henry, Gary N., and Larson, Wiley J., Space Propulsion Analysis and Design, The McGraw-Hill Companies, Inc., New York, NY, 1995. 
29. System Description: Orbital Sciences Corporation, Space Launch Systems, Minotaur Space Launch Vehicle, http://www.orbital.com/SpaceLaunch/Minotaur/index.html.

30. Minotaur I User’s Guide, Release 2.1, Orbital Sciences Corporation, January 2006. 